Article

\title{
Epoxy-Anhydride Vitrimers from Aminoglycidyl Resins with High Glass Transition Temperature and Efficient Stress Relaxation
}

\author{
Michael Giebler ${ }^{1}$, Clemens Sperling ${ }^{1}$, Simon Kaiser ${ }^{1}$, Ivica Duretek ${ }^{2}$ and Sandra Schlögl ${ }^{1, *}$ (] \\ 1 Polymer Competence Center Leoben $\mathrm{GmbH}$, Roseggerstrasse 12, A-8700 Leoben, Austria; \\ michael.giebler@pccl.at (M.G.); clemens.sperling@stud.unileoben.ac.at (C.S.); simon.kaiser@pccl.at (S.K.) \\ 2 Chair of Polymer Processing, Montanuniversitaet Leoben, Otto Gloeckel-Strasse 2, A-8700 Leoben, Austria; \\ ivica.duretek@unileoben.ac.at \\ * Correspondence: sandra.schloegl@pccl.at; Tel.: +43-3842-402-2354
}

Received: 19 April 2020; Accepted: 15 May 2020; Published: 17 May 2020

\begin{abstract}
Epoxy-anhydride vitrimers are covalent adaptable networks, which undergo associative bond exchange reactions at elevated temperature. Their service temperature is influenced by the glass transition temperature $\left(T_{\mathrm{g}}\right)$ as well as the topology freezing transition temperature $\left(T_{\mathrm{v}}\right)$, at which the covalent bond exchange reactions become significantly fast. The present work highlights the design of high- $T_{\mathrm{g}}$ epoxy-anhydride vitrimers that comprise an efficient stress relaxation at elevated temperature. Networks are prepared by thermally curing aminoglycidyl monomers with glutaric anhydride in different stoichiometric ratios. The tertiary amine groups present in the structure of the aminoglycidyl derivatives not only accelerate the curing reaction but also catalyse the transesterification reaction above $T_{\mathrm{V}}$, as shown in stress relaxation measurements. The topology rearrangements render the networks recyclable, which is demonstrated by reprocessing a grinded powder of the cured materials in a hot press. The epoxy-anhydride vitrimers are characterised by a high $T_{\mathrm{g}}$ (up to $140^{\circ} \mathrm{C}$ ) and an adequate storage modulus at $25^{\circ} \mathrm{C}(\sim 2.5 \mathrm{GPa})$, which makes them interesting candidates for structural applications operating at high service temperature.
\end{abstract}

Keywords: vitrimers; glass transition temperature; aminoglycidyl resins

\section{Introduction}

Epoxy resins have a wide range of industrial applications but suffer from a lack of recyclability due to their permanently cross-linked network structure. This changed in 2011 due to the pioneering work of Leibler and his group, who introduced epoxy-based vitrimers, which represent a new class of covalent adaptable networks (CANs) [1]. Vitrimers are thermosets, which are capable of changing their network connectivity by thermally activated bond exchange reactions [2]. The exchange rate of those reactions increases with temperature and becomes macroscopically relevant above the topology freezing transition temperature $\left(T_{\mathrm{v}}\right)$. Below $T_{\mathrm{v}}$, the network structure is frozen, whilst above $T_{\mathrm{V}}$, the network is able to flow macroscopically and fully relax stresses, behaving like a viscoelastic liquid [3-6]. This enables the introduction of new material properties in epoxy-based networks, such as self-healing and recyclability [7-10].

For vitrimers relying on transesterification reactions, an appropriate catalyst is often required to accelerate the thermally activated bond exchange reactions [1]. Previous studies revealed that catalyst type and concentration influence the $T_{\mathrm{V}}$, and several types have been introduced [4]. The most popular types are organic zinc salts, such as zinc acetylacetonate and zinc acetate $[1,11,12]$. The organic guanidine base 1,5,7-triazabicyclo[4.4.0]dec-5-ene is another effective transesterification catalyst, which has been often used in the design of epoxy-based vitrimeric systems $[13,14]$. Recently, Williams and 
co-workers reported that covalently bonded tertiary amines have similar capabilities in catalysing transesterification reactions as the catalysts commonly applied in vitrimers [4]. They reacted primary and secondary amines with an excess of epoxy monomer followed by a curing of the pre-reacted epoxy monomer with a stoichiometric amount of carboxylic acid groups. Dynamic networks with properties comparable to classically catalysed vitrimers were obtained.

Along with the type and concentration of the catalyst, the exchange reaction kinetics in vitrimers is governed by the number of hydroxyl and ester groups in the networks [15,16]. Epoxy-anhydride systems cured with an equimolar ratio of epoxide to anhydride groups are not susceptible to transesterification reactions due the absence of hydroxyl groups [17]. Interestingly, a high number of ester moieties enables exchange reactions even in the absence of ample hydroxyl groups [18]. In addition, Hayashi et al. showed that stress relaxation increases with rising crosslink density in polyester vitrimers, whilst the number of free hydroxyl groups was kept constant [15].

To date, a large variety of different vitrimer systems has been published and attempts have been made to transfer these new materials to industrial applications [19]. However, to the best of our knowledge, the majority of the reported vitrimer systems are elastomeric networks at room temperature, having glass transition temperatures $\left(T_{\mathrm{g}}\right)$ below $100{ }^{\circ} \mathrm{C}$, which limits their applicability in structural components [20-24]. In contrast, high- $\mathrm{T}_{\mathrm{g}}$ vitrimer systems often suffer from slow and insufficient transesterification reactions $[1,4,25]$. This is explained by the lack of free hydroxyl moieties and the low network mobility. In particular, epoxy-anhydride and epoxy-acid vitrimers are typically prepared from non-stoichiometric ratios between the chemical functions of monomer and hardener. A lower content of either acyl groups or carboxylic acid moieties with respect to the hydroxyl groups of the epoxy monomers is employed to ensure a certain number of free hydroxyl moieties necessary for fast transesterifications $[17,23]$. The resulting networks are characterized by a lower cross-link density, which compromises the $T_{\mathrm{g}}$. Studies on vitrimers from bisphenol A diglycidyl ether and glutaric anhydride revealed that the $T_{\mathrm{g}}$ decreases from 68 to $59^{\circ} \mathrm{C}$ by changing the stoichiometry of the resin formulation [17]. In addition, vitrimer networks are often built from epoxy monomers or hardeners with soft and flexible structures to ensure a high mobility of the network. Although soft systems perform well in terms of healing, welding and repairing, they suffer from a low $T_{\mathrm{g}}$.

An elegant approach towards high- $T_{\mathrm{g}}$ networks from bio-based resources was pursued by Zhang and co-workers, who synthesised a tri-functional aromatic epoxy monomer and cured it with methylhexahydrophthalic anhydride (MHHPA) in the presence of $\mathrm{Zn}(\mathrm{acac})_{2}-\mathrm{H}_{2} \mathrm{O}$ as catalyst [23]. The networks were characterised by a $T_{\mathrm{g}}$ of up to $187^{\circ} \mathrm{C}$ and showed reasonable repair properties at elevated temperature $\left(220^{\circ} \mathrm{C}\right)$. They explained the good repair properties of these high- $T_{\mathrm{g}}$ networks by a sufficiently high number of hydroxyl groups, a relatively low rubbery modulus and the non-coplanar structure of the epoxy monomer, which facilitates the increase in mobility of the polymer chains with temperature.

Inspired by this work, we transferred this concept to technically relevant epoxy monomers, which are well known for their ability to produce networks with high $T_{\mathrm{g}}\left(>200^{\circ} \mathrm{C}\right)[26,27]$. In particular, we prepared networks from the tetra-functional $4,4^{\prime}$-methylenebis( $N, N$-diglycidylaniline) (4-DGA) and the tri-functional $\mathrm{N}, \mathrm{N}$-diglycidyl-4-glycidyloxyaniline (3-DGOA) using glutaric anhydride as hardener (Figure 1). Compared to MHHPA, which is a typical hardener for high-performance epoxy-based composites, glutaric anhydride does not contain any rigid aromatic structures contributing to a high $T_{\mathrm{g}}$. However, MHHPA is listed as a substance of very high concern (SVHC) by the European Chemicals Agency, and considering future industrial applications, we chose glutaric anhydride as an alternative hardener. 4-DGA and 3-DGOA not only provide rigid benzene rings for tuning the $T_{\mathrm{g}}$ of the network, but also tertiary amine moieties, which are capable of catalysing both the curing and transesterification reaction of vitrimer systems. Without the addition of a conventional catalyst, networks with a $T_{\mathrm{g}}$ of $140{ }^{\circ} \mathrm{C}$ and a $T_{\mathrm{v}}$ of $200^{\circ} \mathrm{C}$ were obtained, which showed remarkable stress relaxation, enabling the reprocessing and recycling of the materials. 


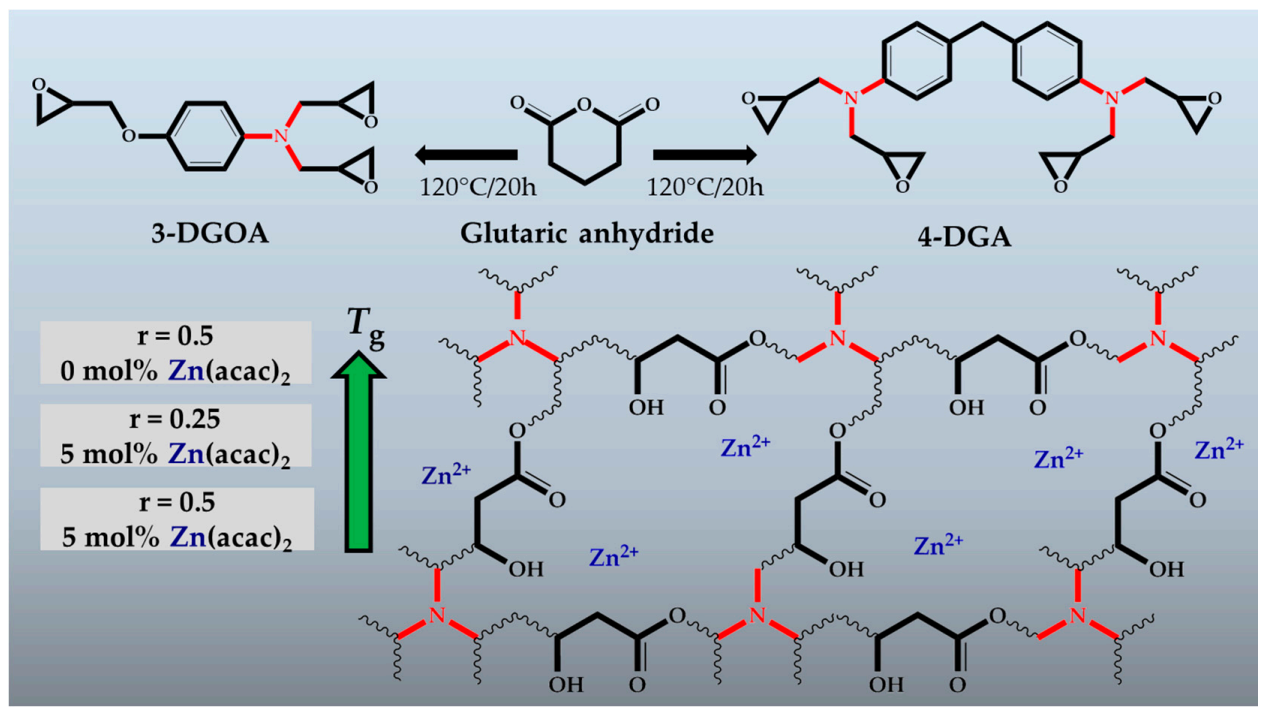

Figure 1. Epoxy-anhydride vitrimers obtained from $4,4^{\prime}$-methylenebis( $N, N$-diglycidylaniline) (4-DGA) and $N, N$-diglycidyl-4-glycidyloxyaniline (3-DGOA) with varying glass transition temperature $\left(T_{\mathrm{g}}\right)$ prepared in the present study. $r$ denotes the stoichiometric ratio, which was defined as $r=$ anhydride equiv/epoxy equiv.

\section{Materials and Methods}

\subsection{Materials}

$N, N$-diglycidyl-4-glycidyloxyaniline, 4,4'-methylenbis( $N, N$-diglycidylaniline), zinc(II)-acetylacetonate hydrate and glutaric anhydride (95\%) were purchased from Sigma Aldrich (St. Lois, MO, USA). The chemicals were used as received. For preparative work, hazardous chemicals and solvents were employed. Reactions must be carried out in a fume hood, and protective clothes and goggles must be used.

\subsection{Methods}

\subsubsection{Preparation of Epoxy-Anhydride Vitrimers}

For the preparation of the catalysed vitrimers, either 4,4'-methylenebis( $N, N$-diglycidylaniline) (4-DGA) or $\mathrm{N}, \mathrm{N}$-diglycidyl-4-glycidyloxyaniline (3-DGOA) were mixed with $\mathrm{Zn}(\mathrm{acac})_{2}-\mathrm{H}_{2} \mathrm{O}$ (at a concentration of $5 \mathrm{~mol} \%$ related to the epoxy groups) in a PTFE beaker and heated to $100{ }^{\circ} \mathrm{C}$. The formulation was stirred at $100^{\circ} \mathrm{C}$ for $10 \mathrm{~min}$ to dissolve the catalyst. Glutaric anhydride was added stepwise and the formulation was stirred for another $10 \mathrm{~min}$ at $100^{\circ} \mathrm{C}$. Air bubbles and low-molecular substances (e.g., acetylacetone from the catalyst) were removed under vacuum for $10 \mathrm{~min}$. For the non-catalysed systems, the formulation was prepared without the addition of $\mathrm{Zn}(\mathrm{acac})_{2}-\mathrm{H}_{2} \mathrm{O}$. Table 1 summarises the composition of the systems under investigation.

Table 1. Composition of the investigated resin formulations. $r$ denotes the stoichiometric ratio, which was defined as $r=$ anhydride equiv/epoxy equiv.

\begin{tabular}{cccccc}
\hline System & 3-DGOA (g) & 4-DGA (g) & Anhydride (g) & Zn(acac) $_{2}$ - $\mathbf{H}_{\mathbf{2}} \mathbf{O}$ (mg) & $r$ \\
\hline 3-DGOA-0.5-Zn & 5 & - & 5.7 & 658 & 0.5 \\
3-DGOA-0.25-Zn & 5 & - & 2.9 & 658 & 0.25 \\
3-DGOA-0.5 & 5 & - & 5.7 & - & 0.5 \\
4-DGA-0.5-Zn & - & 5.7 & 5.7 & 658 & 0.5 \\
4-DGA-0.25-Zn & - & 5.7 & 2.9 & 658 & 0.25 \\
4-DGA-0.5 & - & 5.7 & 5.7 & - & 0.5 \\
\hline
\end{tabular}




\subsubsection{Fourier-Transform Infrared Spectroscopy (FT-IR)}

In order to monitor the progress of the thermally induced ring-opening reaction between the epoxide and the anhydride hardener, FT-IR spectroscopy with a Vertex 70 spectrometer (Bruker, Billerica, MA, USA) was carried out. Sixteen scans were accumulated in transmission mode with a resolution of $4 \mathrm{~cm}^{-1}$. The areas of the IR absorption peaks were calculated with OPUS software (Version 7.0, Bruker, Billerica, MA, USA). For sample preparation, thin films were spin-cast from chloroform solutions $(1 \mathrm{mg} / \mathrm{mL})$ of the resin formulations (Table 1$)$ on a Si wafer.

\subsubsection{Dynamic-Mechanical Thermal Analysis (DMTA)}

For sample preparation, the resin formulations were poured into a pre-heated $\left(120^{\circ} \mathrm{C}\right)$ metal mold and cured for $20 \mathrm{~h}$ at $120^{\circ} \mathrm{C}$. Cured sheets with a thickness of $1.5 \mathrm{~mm}$ were obtained, from which rectangular test specimens $(3 \times 12 \mathrm{~mm})$ were cut. DMTA experiments were carried out with a Mettler Toledo SDTA861e dynamic mechanical analyzer (Columbus, OH, USA) in tensile mode. A clamping length of $9 \mathrm{~mm}$ was chosen, and the measurements were performed in displacement-controlled oscillation of $2.5 \mu \mathrm{m}$ amplitude at $1 \mathrm{~Hz}$. The heating rate was $3 \mathrm{~K} / \mathrm{min}$ from -50 to $230^{\circ} \mathrm{C}$.

\subsubsection{Thermogravimetric Analysis (TGA)}

TGA experiments were performed on a Mettler Toledo (Columbus, OH, USA) TGA/DSC1 thermogravimetric analyzer. Measurements were done under nitrogen atmosphere. The samples were heated from 25 to $900^{\circ} \mathrm{C}$ at a heating rate of $10^{\circ} \mathrm{C} / \mathrm{min}$ and the data were analysed with the STAR software of Mettler-Toledo (Columbus, OH, USA).

\subsubsection{Stress Relaxation}

Stress relaxation was determined in torsion mode using an MCR 501 rheometer (Anton Paar, Graz, Austria) equipped with a rectangular torsion fixture. The heating chamber was continuously purged with nitrogen at a volume flow of $1 \mathrm{~m}^{3} / \mathrm{h}$. Rectangular samples with a uniform thickness of $1.5 \mathrm{~mm}$, a length of $30 \mathrm{~mm}$ and a width of $5 \mathrm{~mm}$ were heated to the desired measurement temperature $\left(160-280^{\circ} \mathrm{C}\right)$ and equilibrated for $20 \mathrm{~min}$. A constant elongational force of $0.1 \mathrm{~N}$ was applied to ensure a stable position of the sample. After temperature equilibration, a deflection of $1 \%$ was applied and kept constant during the measurements, whilst the torque was monitored over time.

\subsubsection{Recycling of Vitrimers}

The cured 3-DGOA-0.5-Zn and 4-DGA-0.5-Zn networks were grinded with a ball mill for $90 \mathrm{~s}$ and $30 \mathrm{~Hz}$. The resulting powder was molded in discs with a diameter of $25 \mathrm{~mm}$ with a vacuum press (Collin, Ebersberg, Germany) applying a pressure of 5 bar for $40 \mathrm{~min}$ at $220^{\circ} \mathrm{C}$. In addition, molded test bars were prepared in a PVT 100 (SWO Polymertechnik, Krefeld, Germany) operating at 500 bar. The pressure was applied at $250{ }^{\circ} \mathrm{C}$ for $5 \mathrm{~min}$.

\section{Results and Discussion}

\subsection{Design and Curing of High-T $T_{g}$ Epoxy-Anhydride Vitrimers}

Epoxy-anhydride networks were prepared by reacting either $N, N$-diglycidyl-4-glycidyloxyaniline (3-DGOA) or 4,4'-methylenbis( $N, N$-diglycidylaniline) (4-DGA) with glutaric anhydride at different stoichiometric ratios and catalyst contents (Table 1). The stoichiometric ratio $r$ was defined as $r=$ anhydride equiv/epoxy equiv and amounted to either 0.5 or 0.25 . In technical applications, $r$ typically ranges between 0.5 and 0.9 to obtain optimum mechanical and thermal properties of the thermosets [28]. However, aiming at the fabrication of hydroxyl ester networks with a high number of free -OH groups, we also prepared epoxy-anhydride systems with a high excess of epoxy groups $(r=0.25)$. 
For the preparation of the $\mathrm{Zn}(\mathrm{acac})_{2}-\mathrm{H}_{2} \mathrm{O}$ catalysed epoxy-anhydride networks, the transesterification catalyst was dissolved in the particular aminoglycidyl monomer, which was preheated at $100{ }^{\circ} \mathrm{C}$. Next, the anhydride was added stepwise, and after obtaining a homogeneous mixture the curing was carried out at $120^{\circ} \mathrm{C}$.

The curing kinetics was characterised using FT-IR spectroscopy. Figure $2 \mathrm{~d}$ shows the FT-IR spectra of 3-DGOA-0.5-Zn prepared with $r=0.5$, prior to and after thermal curing at $120^{\circ} \mathrm{C}$. After a cure time of $3 \mathrm{~h}$, the two bands ( 1860 and $1778 \mathrm{~cm}^{-1}$ ) related to carbonyl of the anhydride groups disappeared whilst a new band was observed at $1740 \mathrm{~cm}^{-1}$, which is attributed to the carbonyl group of the newly formed ester linkages. A broad absorption band appeared at $3482 \mathrm{~cm}^{-1}$, which is associated with the formation of hydroxyl groups. Moreover, the epoxy band at $910 \mathrm{~cm}^{-1}$ and the partly overlapping $\mathrm{C}-\mathrm{O}$ absorption band $\left(931 \mathrm{~cm}^{-1}\right)$ of the anhydride hardener disappeared. Thus, the results demonstrate the successful formation of hydroxyl ester linkages via the nucleophilic ring-opening reaction between the aminoglycidyl epoxy monomers and glutaric anhydride. Full conversion of the functional groups is obtained in under $3 \mathrm{~h}$, and no significant change in the bands was observed for extended curing of $20 \mathrm{~h}$.

The fast curing can be explained by the catalytic effect of $\mathrm{Zn}(\mathrm{acac})_{2}-\mathrm{H}_{2} \mathrm{O}$. It is well known that organic zinc salts take part in the curing reaction due to their nucleophilic nature [29,30]. By dissolving the zinc salt in the epoxy monomers, the $\mathrm{Zn}^{2+}$ ions are able to substitute the organic ligands with the oxygen of the epoxide ring. Subsequently, ring opening of the epoxide groups takes place, and after adding the anhydride, carboxylate-ions are formed (Figure 2a), which undergo a nucleophilic ring-opening reaction with the epoxy moieties. Ester groups and additional carboxylate anions are formed, which leads to a perpetuation of the ring-opening reaction. The reaction follows an anionic alternating copolymerization, yielding a polyester network. The ligands typically evaporate during solvation and curing and the $\mathrm{Zn}^{2+}$ ions remain in the cured network. In addition, water is released from the catalyst at high temperature, which further accelerates the reaction by hydrolysing the anhydride ring under the formation of carboxylic acids. Furthermore, it should be noted that a homopolymerisation of the epoxy groups can take place as an alternative reaction pathway at an excess of epoxy monomers and at low curing temperatures [27]. At $1080 \mathrm{~cm}^{-1}$, a small band is observed, which might be related to the $\mathrm{C}-\mathrm{O}$ absorption band of ethers [31]. However, the competition between esterification and etherification cannot be clearly identified since $\mathrm{C}-\mathrm{O}$ bands of the ester moieties at $1250 \mathrm{~cm}^{-1}$ overlap with ether bands $\left(1200-1080 \mathrm{~cm}^{-1}\right)$ in the fingerprint area.

Increasing the excess of epoxy moieties (catalysed formulations cured with $r=0.25$ ), the IR absorption band of the $-\mathrm{OH}$ groups $\left(3482 \mathrm{~cm}^{-1}\right)$ significantly increases in cured samples, whilst the band area of the formed ester bonds $\left(1740 \mathrm{~cm}^{-1}\right)$ is less pronounced (Figure 2e). Full conversion of the anhydride moieties is observed, but the consumption of the epoxy groups is not complete, which is indicated by the high intensity of the $\mathrm{C}-\mathrm{O}$ band at $1234 \mathrm{~cm}^{-1}$ and the remaining $\mathrm{C}-\mathrm{O}$ band at 910 $\mathrm{cm}^{-1}$ [27]. The results clearly show the presence of non-reacted epoxy groups ( $\left.\sim 6 \%\right)$ giving rise to an incomplete homopolymerization of 3-DGOA. This is mainly due to diffusion limitations of the monomers above the gel point and which are typically observed in aromatic epoxies at high degrees of conversion (>90\%) [32-34]. During the course of the curing reaction, the mobility of the monomers decreases due to the high viscosity of the matrix and the reaction becomes diffusion controlled since the diffusion of reactive species toward each other is hindered.

This behavior is even more pronounced in catalysed formulations with 4-DGA, since the epoxy monomers comprise a higher functionality and the rigid bi-functional aromatic structure makes them less mobile. Thus, even in 4-DGA networks cured with $r=0.5$, a small amount of epoxy groups $(\sim 4 \%)$ remain unreacted after curing at $120^{\circ} \mathrm{C}$ for $20 \mathrm{~h}$ (Figure $2 \mathrm{f}$ ). In addition, the band area of the $-\mathrm{OH}$ groups $\left(3482 \mathrm{~cm}^{-1}\right)$ is smaller than in spectra of the cured 3-DGOA counterpart, indicating a lower number of $-\mathrm{OH}$ groups. Since a high number of $\mathrm{OH}$ groups is beneficial in the transesterification reaction, 4-DGA networks are expected to be less efficient in stress relaxation experiments [18]. 


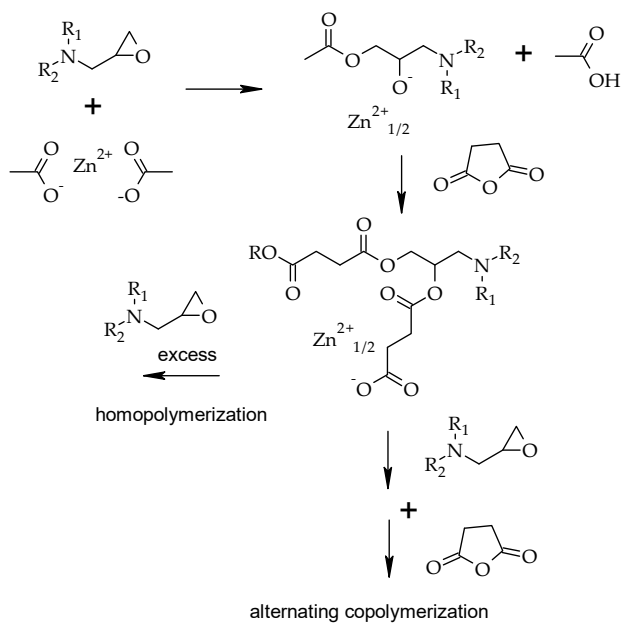

(a)

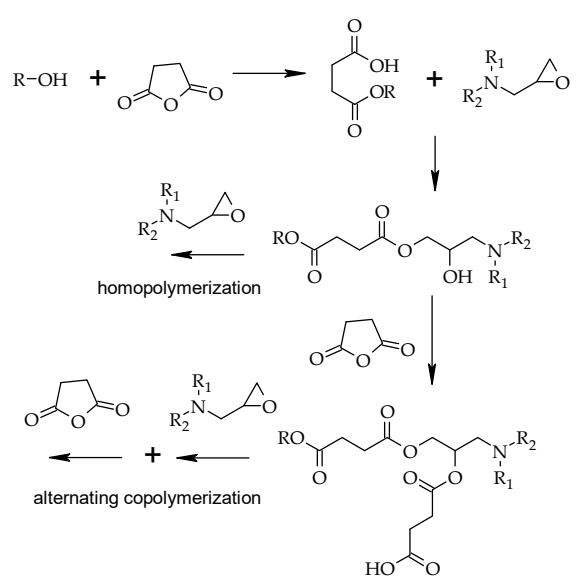

(c)

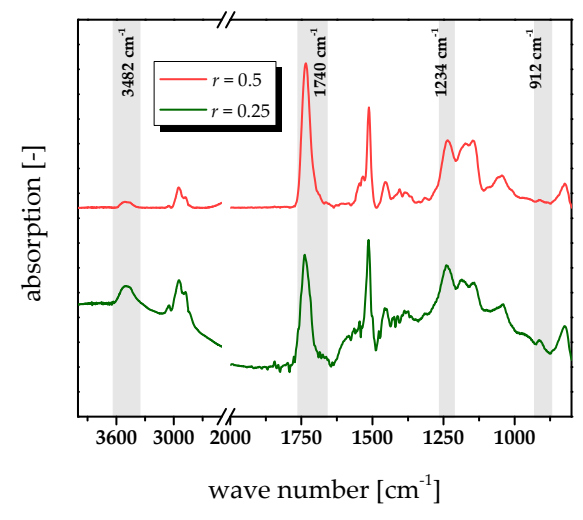

(e)

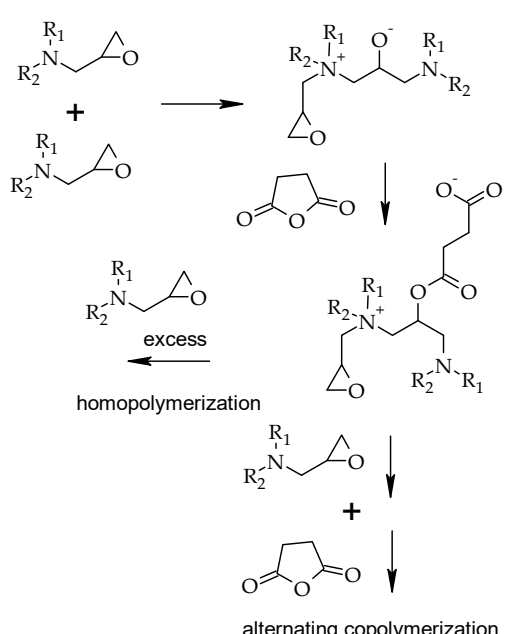

(b)

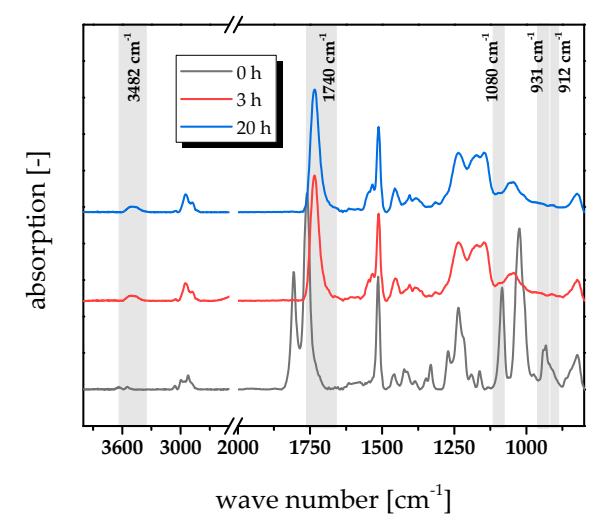

(d)

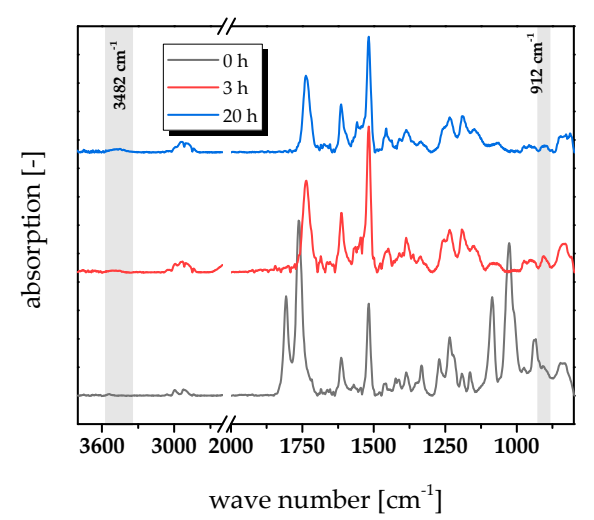

(f)

Figure 2. Mechanism of the ring opening reaction of epoxies with anhydrides in the presence of (a) zinc salts and (b) tertiary amines as catalysts or (c) without catalyst. (d) FT-IR spectra of catalysed 3-DGOA/glutaric anhydride systems cured with $r=0.5$, prior to and after curing at $120^{\circ} \mathrm{C}$ for 3 and $20 \mathrm{~h}$. (e) FT-IR spectra of catalysed 3-DGOA/glutaric anhydride systems as a function of the stoichiometric ratio, after curing at $120^{\circ} \mathrm{C}$ for $20 \mathrm{~h}$. (f) FT-IR spectra of catalysed 4-DGA/glutaric anhydride systems cured with $r=0.5$, prior to and after curing at $120^{\circ} \mathrm{C}$ for 3 and $20 \mathrm{~h}$. 
In addition, non-catalysed networks from 3-DGOA and 4-DGA with $r=0.5$ were prepared. In the absence of a catalyst, the curing of epoxy-anhydride systems follows a step growth reaction (Figure 2c) [32]. Traces of water or impurities with -OH groups start the reaction by opening the anhydride rings to form carboxylic acid groups. Once formed, the carboxylic acid groups undergo a nucleophilic ring opening reaction with the epoxy groups generating $-\mathrm{OH}$ groups, which react with further anhydride moieties [35]. For the curing of aminoglycidyl monomers, previous studies revealed that the tertiary amine groups of epoxy monomers can catalyse the reaction [27].

In the base catalysed ring-opening reaction, the tertiary amine groups open the epoxy rings under the formation of alkoxides (Figure $2 b$ ) $[32,34,36]$. The alkoxides react with anhydride groups yielding carboxylate anions, which are again able to open epoxy moieties. The reaction also follows an anionic alternating copolymerization and yields a polyester network. As with the zinc catalysed system, homopolymerisation of the epoxy moieties can occur in resin formulations with an excess of epoxy monomers [35].

From FT-IR data it can be obtained that the final monomer conversions of systems without $\mathrm{Zn}(\mathrm{acac})_{2}-\mathrm{H}_{2} \mathrm{O}$ are comparable to catalysed ones, albeit they are reached at longer curing times. This is in good agreement with previous work on epoxy-anhydride systems demonstrating that the catalyst mainly influences the cure rate but not the final monomer conversion [34]. To ensure maximum conversion of the monomers, which was monitored by the disappearance of the epoxy band at $910 \mathrm{~cm}^{-1}$, all networks were cured at $120^{\circ} \mathrm{C}$ for $20 \mathrm{~h}$.

\subsection{Thermal and Thermo-Mechanical Properties of High- $T_{g}$ Epoxy-Anhydride Vitrimers}

The different cure mechanism of catalysed and non-catalysed systems together with the varying degree of homopolymerisation and residual monomers are expected to affect the thermomechanical properties of the networks. The $T_{\mathrm{g}}$ values were determined from DMTA measurements by taking the maxima of the $\tan \delta$ curve and are provided in Table 2. In particular, curing of glutaric anhydride with 4-DGA yields networks with higher $T_{\mathrm{g}}$ than the counterparts cured with 3-DGOA, which is explained by the higher functionality and rigidity of the tetra-functional epoxy monomer. Independent of the epoxy monomer, the $T_{\mathrm{g}}$ of non-catalysed networks is higher than the catalysed ones. This behaviour was also found in other epoxy-anhydride networks and is related to a faster curing of the resin in the presence of a catalyst, which affects the network structure and leads to a lower cross-linking density [34,37]. With increasing concentration of the catalyst, this effect is more pronounced and a steady decrease of the $T_{\mathrm{g}}$ values is obtained [38].

Table 2. Characteristic properties of epoxy-anhydride vitrimers under investigation: $T_{\mathrm{g}}$ values derived from dynamic-mechanical thermal analysis DMTA measurements and $T_{\mathrm{v}}$ and $E_{\mathrm{a}}$ data obtained from Arrhenius plots, in which $\mathrm{R}^{2}$ denotes the coefficient of determination.

\begin{tabular}{ccccc}
\hline System & $\boldsymbol{T}_{\mathrm{g}}\left({ }^{\circ} \mathbf{C}\right)$ & $\boldsymbol{T}_{\mathbf{v}}\left({ }^{\circ} \mathbf{C}\right)$ & $\boldsymbol{E}_{\mathrm{a}}(\mathbf{k J} / \mathbf{m o l})$ & $\boldsymbol{R}^{\mathbf{2}}$ \\
\hline 3-DGOA-0.25-Zn & 120 & 113 & 53 & 0.97 \\
3-DGOA-0.5-Zn & 112 & 190 & 87 & 0.95 \\
3-DGOA-0.5 & 125 & 241 & 154 & 0.99 \\
4-DGA-0.25-Zn & 122 & 188 & 111 & 0.99 \\
4-DGA-0.5-Zn & 130 & 227 & 158 & 0.96 \\
4-DGA-0.5 & 140 & 238 & 161 & 0.99 \\
\hline
\end{tabular}

Interestingly, catalysed 3-DGOA networks cured with $r=0.25$ show a higher $T_{\mathrm{g}}$ than networks with $r=0.5$. This is explained by the homopolymerisation of the epoxy monomers, which is more pronounced at a higher excess of epoxy moieties and is catalysed by the - $\mathrm{OH}$ groups formed during the ring opening reaction between anhydride and epoxy moieties [27]. The additionally formed ether crosslinks further shift the $T_{\mathrm{g}}$ of the networks to higher values. However, in the respective DMTA 
curve, only a one-step change in modulus and a single peak in $\tan \delta$ is observed, which indicates a rather homogeneous network structure (Figure 3a).

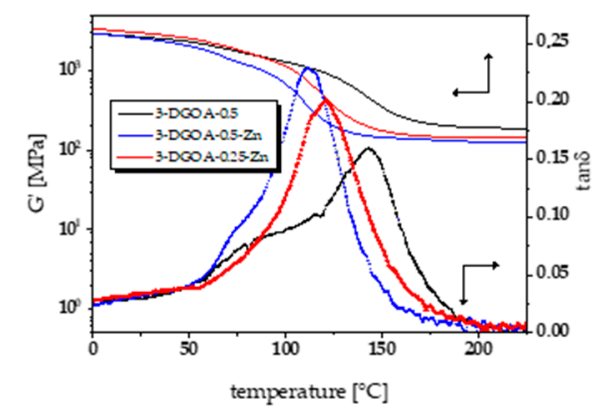

(a)

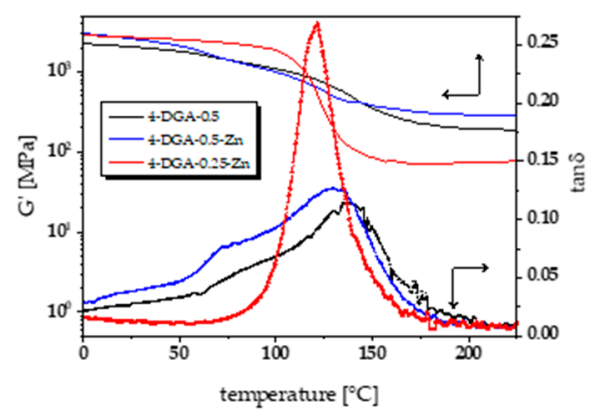

(b)

Figure 3. Storage modulus $\left(G^{\prime}\right)$ and $\tan \delta$ curves of epoxy-anhydride vitrimers from (a) 3-DGOA and (b) 4-DGA.

This is in good agreement with previous work on epoxy-anhydride vitrimers prepared from rigid epoxy monomers [23].

In contrast, non-catalysed 3-DGOA networks prepared with $r=0.5$ show a significantly broader peak in $\tan \delta$ and a shift of the maximum $\tan \delta$ to higher values. The higher heterogeneity of the networks is explained by the different cure mechanism of non-catalysed resins favouring the homopolymerisation of the epoxy monomers. Thus, non-catalysed networks are expected to have an even higher number of ether crosslinks than catalysed ones, leading to an additional transition at higher temperatures. The results suggest that the degree of homopolymerisation increases in the order of 3-DGOA-0.5-Zn < 3-DGOA-0.25-Zn < 3-DGOA-0.5.

A comparable behaviour and shift in the maximum $\tan \delta$ values is also observed in the DMTA curves of non-catalysed 4-DGA networks (Figure 3b). However, an onset of a sub-glass transition is observed at around $20^{\circ} \mathrm{C}$, which indicates an incompletely cured network. 4-DGA-0.5-Zn systems follow the same trend giving rise to an incomplete homopolymerisation of the epoxy monomers. This is also corroborated by FT-IR data showing a lower number of -OH groups and a higher content of non-reacted epoxy moieties.

In contrast, 4-DGA-0.25-Zn networks are characterized by a narrow peak in the $\tan \delta$ curve without an onset of a sub-glass transition region, giving rise to a highly homogeneous network structure. This behaviour is also observed in networks from 3-DGOA, as the DMTA data indicate the highest homogeneity in 3-DGOA-0.25-Zn systems. Thus, the results suggest that the network structure is comprised of well intertwined epoxy-anhydride and homopolymerised epoxy domains, since only a single and narrow peak is observed in the tan $\delta$ curve. Interestingly, the $T_{\mathrm{g}}$ of 4 -DGA- $0.25-\mathrm{Zn}$ systems is lower than the $T_{\mathrm{g}}$ of 4-DGA-0.5-Zn networks, although a higher content of epoxy monomers is expected to yield a higher degree of homopolymerization and thus a higher content of ether linkages. This might be explained by diffusion limitations of the tetra-functional epoxy monomers, which lead to incomplete monomer conversions, as shown in the FT-IR studies, and highly heterogeneous network structures as obtained from the broad $\tan \delta$ curve of 4-DGA-0.5-Zn systems. We assume that diffusion limitations of 4-DGA lead to heterogeneous networks, which contain homopolymerised epoxy domains with higher chain lengths than in 4-DGA-0.25-Zn networks. The higher chain length might facilitate the formation of separate domains of homopolymerised 4-DGA, which not only result in a broader tan $\delta$ curve but also in a stronger shift of the maximum of the tan $\delta$ curve to higher temperatures, even at a lower content of epoxy monomers.

Along with thermo-mechanical properties, the thermal stability of the epoxy-anhydride networks as a function of stoichiometry, catalyst and type of epoxy monomer was determined using TGA (Figure 4). By adding $\mathrm{Zn}(\mathrm{acac})_{2}-\mathrm{H}_{2} \mathrm{O}$ as catalyst, 3-DGOA-0.5 systems show a decrease in initial 
weight loss temperature $\left(T_{\mathrm{i}}\right)$ from $\sim 320$ to $280^{\circ} \mathrm{C}$ together with an increase in weight loss at $900{ }^{\circ} \mathrm{C}\left(w_{900}\right)$ from $11 \%$ to $23 \%$. The higher thermal stability of non-catalysed systems is related to the higher degree of homopolymerisation, as observed in DMTA experiments. Since ether groups comprise a higher thermal stability than ester moieties, the thermal properties of the related networks are improved [23]. This is also confirmed by the even higher thermal stability of catalysed networks prepared with $r=0.25$ (3-DGOA-0.25-Zn). The further increase in both $T_{\mathrm{i}}$ (from 280 to $300{ }^{\circ} \mathrm{C}$ ) and $w_{900}$ (from $23 \%$ to $28 \%$ ) is mainly related to the higher number of ether crosslinks, formed at an excess of epoxy monomers in the resins formulation.

In contrast to catalyst and stoichiometry, the type of diglycidylaniline derivative used in the present study has no significant influence on the thermal stability of the epoxy-anhydride networks. Although DMTA curves indicate a higher heterogeneity in 4-DGA-anhydride networks, the weight loss curves of networks from 4-DGA and 3-DGOA are comparable and exhibit a one-stage decomposition process. As an example, Figure $4 \mathrm{~b}$ compares the weight loss curves of catalysed networks from 4-DGA and 3-DGOA, and both networks have nearly identical $T_{\mathrm{i}}$ and $w_{900}$ values.

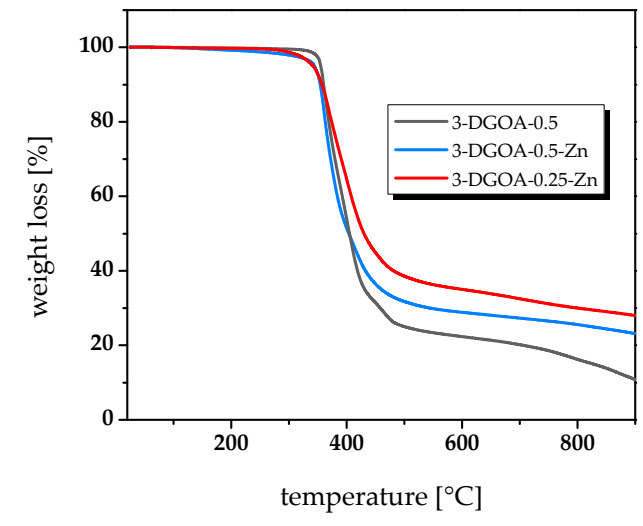

(a)

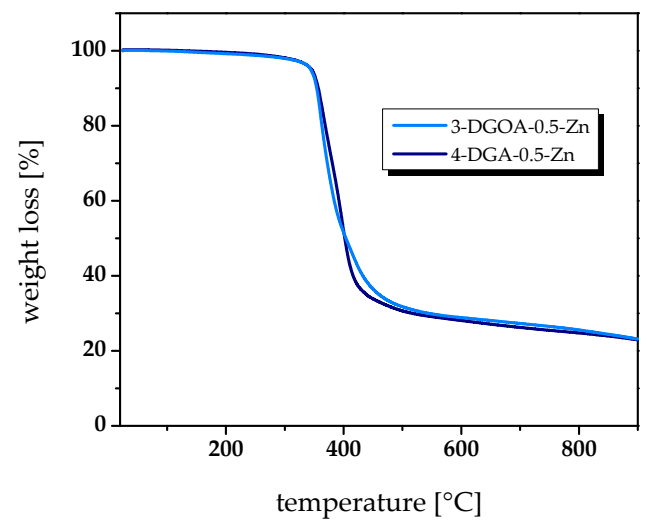

(b)

Figure 4. TGA curves of epoxy-anhydride vitrimers. (a) Influence of catalyst and stoichiometry on the thermal stability of vitrimers from 3-DGOA and glutaric acid and (b) influence of the type of epoxy monomer (3-DGOA vs. 4-DGA) on the thermal stability of catalysed vitrimers (epoxy and anhydride groups in stoichiometry).

\subsection{Thermally Adaptable Properties and Reprocessability of High-T $T_{g}$ Epoxy-Anhydride Vitrimers}

The thermally triggered topology rearrangements of the networks were studied using stress relaxation experiments. Since the epoxy-anhydride vitrimers under investigation comprised a $T_{\mathrm{g}}$ in the range between 113 and $140{ }^{\circ} \mathrm{C}$ and were stable at least up to $280{ }^{\circ} \mathrm{C}$, the stress relaxation experiments were carried out between 160 and $280^{\circ} \mathrm{C}$. Consequently, thermal degradation of the networks was avoided during the rheological measurements, whilst a high mobility of the chain segments was ensured as the studies were carried out above the networks' $T_{\mathrm{g}}$. In Figure $5 \mathrm{a}, \mathrm{b}$, the evolution of the relaxation modulus at $220^{\circ} \mathrm{C}$ as a function of time is shown for 3-DGOA and 4-DGA networks, respectively. All networks comprise a distinctive stress relaxation, even networks without $\mathrm{Zn}(\mathrm{acac})_{2}-\mathrm{H}_{2} \mathrm{O}$, albeit at a lower relaxation rate. Thus, the results clearly show that the tertiary amines of the epoxy monomers are able to catalyse the transesterification exchange reaction in the networks. As expected, the relaxation rate increases with the addition of $\mathrm{Zn}(\mathrm{acac})_{2}-\mathrm{H}_{2} \mathrm{O}$ giving rise to acceleration of the bond exchange reactions in the presence of the catalyst. In addition, networks prepared with $r=0.25$ comprise a higher relaxation rate than the ones containing a lower excess of epoxy groups $(r=0.5)$. This is mainly attributed to the higher degree of epoxy homopolymerisation leading to a higher number of terminal $-\mathrm{OH}$ groups in the networks, which is well known to be advantageous for efficient stress relaxation [18]. In contrast, the limited availability of -OH groups leads to the lower relaxation rate observed in 4-DGA 
networks. FT-IR experiments have already showed that 4-DGA networks suffer from a lower content of -OH groups, which clearly affects the rate of bond exchange reactions at elevated temperature.

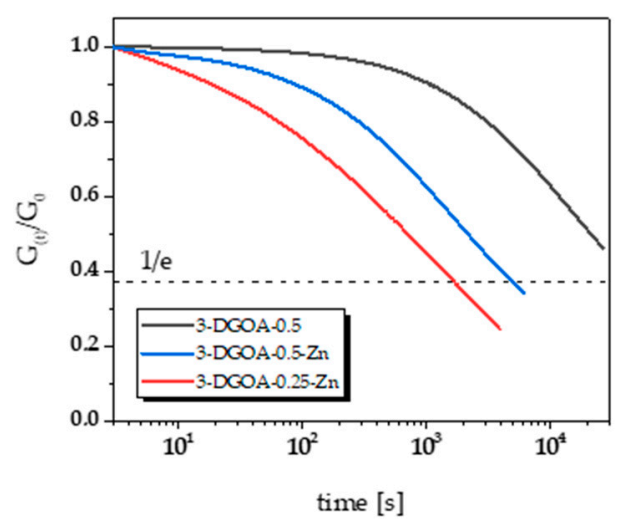

(a)

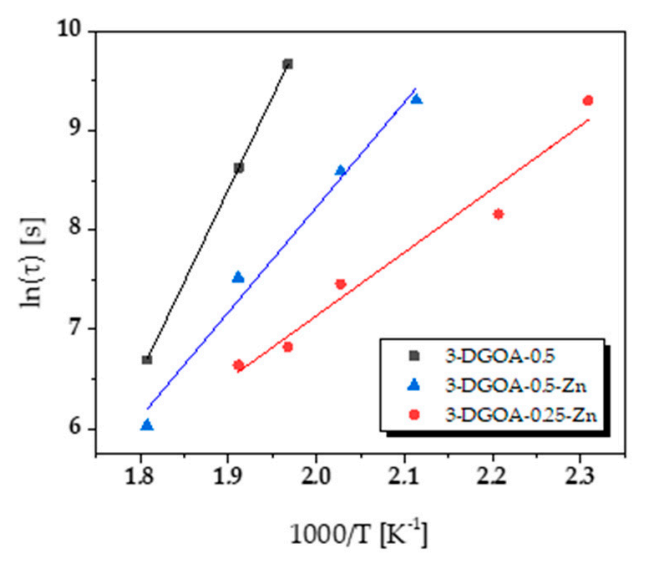

(c)

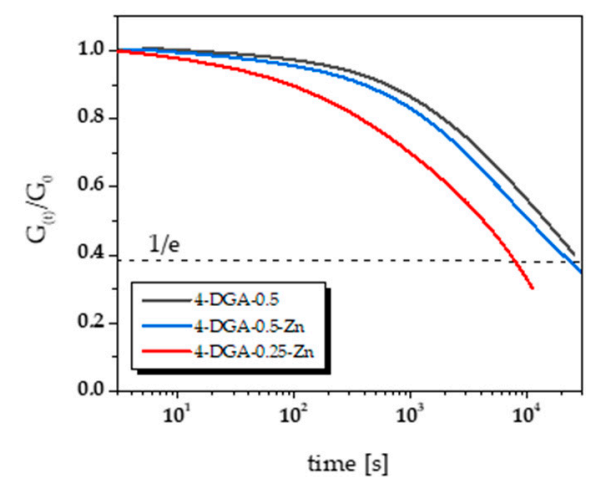

(b)

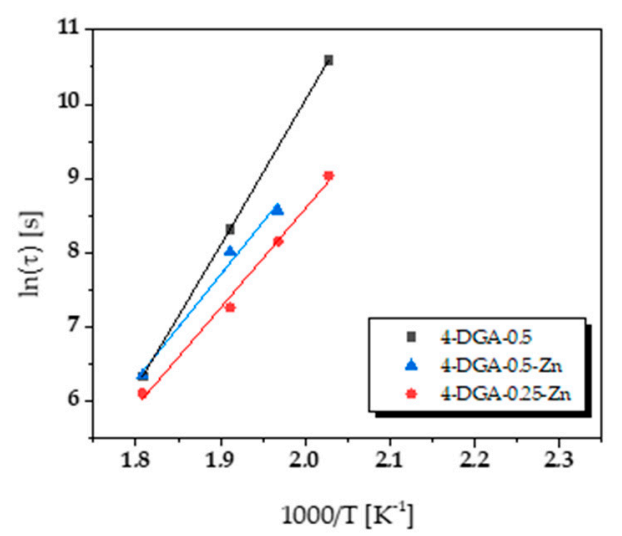

(d)

Figure 5. Normalised stress relaxation curves of epoxy-anhydride networks from (a) 3-DGOA and (b) 4-DGA obtained at $220^{\circ} \mathrm{C}$. Arrhenius plot of the measured relaxation times from epoxy-anhydride networks obtained with (c) 3-DGOA and (d) 4-DGA.

Upon determining the stress relaxation curves at different temperatures, the topology freezing temperature $\left(T_{\mathrm{V}}\right)$ can be calculated from the respective Arrhenius plot [1]. Below $T_{\mathrm{V}}$, the networks behave like thermosets since the exchange reaction rate is very low and the dynamic bonds are essentially frozen. Increasing the temperature above $T_{\mathrm{V}}$, the transition from an elastic solid to a viscoelastic liquid occurs. The viscosity gradually decreases with temperature and follows the Arrhenius law. Following the Maxwell model, the relaxation times $\left(\tau^{*}\right)$ were determined as the time needed to relax to $1 / \mathrm{e}$ of the initial stress. Since the $\tau^{*}$ of vitrimers follow the Arrhenius law with the temperature, it can be expressed as $\tau_{(\mathrm{T})}=\tau_{0} \exp \left(E_{\mathrm{a}} / \mathrm{RT}\right) . T_{\mathrm{v}}$ values are obtained by extrapolation from the Arrhenius plot [4]. The $T_{\mathrm{V}}$ values of the epoxy-anhydride networks under investigation are shown in Table 2, and the related Arrhenius plots of the relaxation times are provided in Figure $5 \mathrm{c}, \mathrm{d}$.

The activation energy $\left(E_{\mathrm{a}}\right)$ for the topology freezing and the $T_{\mathrm{v}}$ values significantly differ for the networks investigated. As already observed for the stress relaxation curves at $220^{\circ} \mathrm{C}$, the bond exchange reactions are accelerated by $\mathrm{Zn}(\mathrm{acac})_{2}-\mathrm{H}_{2} \mathrm{O}$ and an increasing number of $-\mathrm{OH}$ groups in the network, which leads to a decrease in both $T_{\mathrm{v}}$ and $E_{\mathrm{a}}$. The high number of $-\mathrm{OH}$ groups might also explain the comparatively low $T_{\mathrm{v}}$ of the 3-DGOA-0.25-Zn network, which is in the range of the $T_{\mathrm{g}}$ of the network. In contrast, all other networks comprise a $T_{\mathrm{v}}$ well above the $T_{\mathrm{g}}$. 
This behavior might be mainly related to the different degrees of homopolymerisation of the epoxy monomers in the networks. On the one hand, homopolymerisation leads to the formation of polymer chains with terminal -OH groups, which facilitate the transesterification and lead to lower $T_{\mathrm{v}}$ values. On the other hand, the higher number of ether bonds formed by homopolymerisation shifts the $T_{\mathrm{g}}$ of the networks to higher values. In 3-DGOA-0.25-Zn networks, this effect is particularly pronounced, leading to a $T_{\mathrm{v}}$ value which is lower than the $T_{\mathrm{g}}$. In contrast, in 4-DGA-0.25-Zn networks, the number of $-\mathrm{OH}$ groups is significantly lower, as shown by FT-IR data. Thus, a $T_{\mathrm{v}}$ value $\left(188^{\circ} \mathrm{C}\right)$ is obtained, which is higher than the $T_{\mathrm{g}}$ of the network $\left(122{ }^{\circ} \mathrm{C}\right)$. Although non-catalysed networks comprise a higher degree of homopolymerisation than the catalysed counterparts, they exhibit significantly higher $T_{\mathrm{v}}$ values of 238 (4-DGA-0.5) and $241{ }^{\circ} \mathrm{C}$ (3-DGOA-0.5). The distinctive increase in $T_{\mathrm{v}}$ is mainly related to the different reactivity of organic zinc salts compared to tertiary amines in the catalysis of the transesterification reaction. Thus, even if the non-catalysed networks are characterized by the highest $T_{\mathrm{g}}$ (up to $140^{\circ} \mathrm{C}$ ), the values are not able to exceed the corresponding $T_{\mathrm{V}}$ data. Similar behavior of vitrimers was previously discussed by Du Prez and co-workers in their study on the material characteristics of vitrimers [2].

The dynamic nature of the networks was exploited to thermally reprocess the epoxy-anhydride systems. To demonstrate the recyclability of the networks, cured test plates of 3-DGOA-0.5-Zn and 4-DGA-0.5-Zn were grinded to a fine powder (Figures $6 \mathrm{a}$ and $7 \mathrm{a}$ ), which was remolded in a press at 5 bar and $220^{\circ} \mathrm{C}$. The grain boundaries of the resin particles were still visible in the remolded test specimen (Figures $6 b$ and $7 b$ ). However, the majority of the grain boundaries vanished (Figure $6 c, d$ and Figure $7 \mathrm{c}, \mathrm{d})$ if the molding was carried out both at higher temperature $\left(250{ }^{\circ} \mathrm{C}\right)$ and pressure (500 bar). In future work the mechanical properties and ageing of the various networks will be tested as a function of the applied recycling parameters.
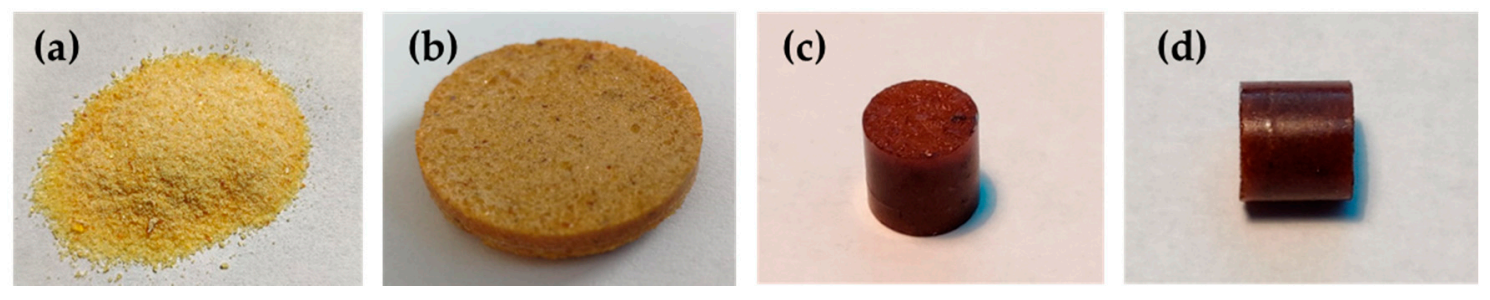

Figure 6. (a) Grinded powder from 3-DGOA-0.5-Zn networks. (b) Remolded test specimen obtained by applying 5 bar at $220^{\circ} \mathrm{C}$. The diameter of the disc is $25 \mathrm{~mm}$. (c,d) Remolded test specimen obtained by applying 500 bar at $250{ }^{\circ} \mathrm{C}$. The diameter of the cylinder is $7 \mathrm{~mm}$.
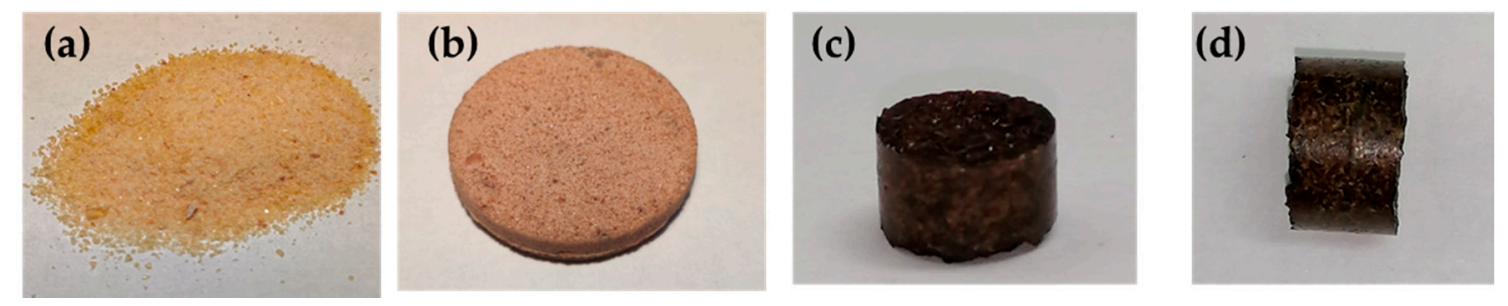

Figure 7. (a) Grinded powder from 4-DGA-0.5-Zn networks. (b) Remolded test specimen obtained by applying 5 bar at $220^{\circ} \mathrm{C}$. The diameter of the disc is $25 \mathrm{~mm}$. (c,d) Remolded test specimen obtained by applying 500 bar at $250{ }^{\circ} \mathrm{C}$. The diameter of the cylinder is $7 \mathrm{~mm}$.

\section{Conclusions}

Epoxy-anhydride vitrimers were prepared using thermal curing of tri- and tetra-functional aminoglycidyl epoxy monomers with glutaric anhydride. Cured networks were obtained at $120^{\circ} \mathrm{C}$ without the addition of a catalyst, since the tertiary amine groups present in the structure of the epoxy monomers were able to accelerate the nucleophilic ring-opening reaction. Final monomer conversions decreased with rising functionality of the epoxy monomers due to diffusion limitations of 
the monomers at high degrees of conversion. By adding $\mathrm{Zn}(\mathrm{acac})_{2}-\mathrm{H}_{2} \mathrm{O}$ as transesterification catalyst, the curing was significantly accelerated. However, incomplete conversion of the epoxy groups was observed in networks with a high excess of epoxy monomer $(r=0.25)$. A higher content of epoxy monomer gave rise to the formation of ether linkages via homopolymerisation, which shifted the $T_{\mathrm{g}}$ and the thermal stability of the networks to higher values. The highest $T_{\mathrm{g}}\left(140^{\circ} \mathrm{C}\right)$ was obtained with non-catalysed 4-DGA/glutaric anhydride systems, which were also able to relax stresses adequately. The results evidence that the tertiary amine groups within the structure of the epoxy monomers catalyse the transesterification exchange reaction, albeit at lower rates than networks with $\mathrm{Zn}(\mathrm{acac})_{2}-\mathrm{H}_{2} \mathrm{O}$. Along with the zinc salt, the relaxation rate increased with rising degree of homopolymerisation, which is related to a higher number of terminal $-\mathrm{OH}$ groups in the networks. In particular, fast stress relaxation at a low $T_{\mathrm{v}}\left(113{ }^{\circ} \mathrm{C}\right)$ was obtained in catalysed 3-DGOA/glutaric anhydride networks prepared with $r=0.25$. Furthermore, the thermally activated bond exchange reactions were exploited to reprocess the cured networks. Successful remoulding of a grinded powder was demonstrated, and in further work the influence of the reprocessing parameters on mechanical performance and ageing stability will be studied in detail. The high $T_{\mathrm{g}}$ paired with the efficient stress relaxation and ability towards reprocessing makes this type of epoxy-anhydride vitrimers interesting candidates for structural applications operating at high service temperature.

Author Contributions: Conceptualization, M.G. and S.S.; methodology, M.G., C.S., S.K. and I.D.; validation, M.G., S.K. and S.S.; investigation M.G., C.S., S.K. and I.D.; resources, S.S.; data curation, C.S.; writing-original draft preparation, M.G. and S.S.; writing-review and editing, M.G., S.K., I.D. and S.S.; supervision, S.S.; project administration, S.S.; funding acquisition, S.S. All authors have read and agreed to the published version of the manuscript.

Funding: This research was funded by the Austrian Research Promotion Agency (FFG), grant number 21647048.

Acknowledgments: The research work was performed within the COMET-Module "Chemitecture" (project-no.: 21647048) at the Polymer Competence Center Leoben GmbH (PCCL, Austria) within the framework of the COMET-program of the Federal Ministry for Transport, Innovation and Technology and the Federal Ministry for Digital and Economic Affairs with contributions by the Chair of Polymer Processing (Montanuniversitaet Leoben, Austria). The PCCL is funded by the Austrian Government and the State Governments of Styria, Upper and Lower Austria. The authors thank Julia Gössmann (Montanuniversitaet Leoben) for her support in the rheological measurements and Miriam Ehrnhöfer-Reßler and Monika Koch (FH Joanneum, University of Applied Sciences, Austria) for grinding the vitrimer networks.

Conflicts of Interest: The authors declare no conflicts of interest.

\section{References}

1. Montarnal, D.; Capelot, M.; Tournilhac, F.; Leibler, L. Silica-Like Malleable Materials from Permanent Organic Networks. Science 2011, 334, 965-968. [CrossRef]

2. Denissen, W.; Winne, J.M.; Du Prez, F.E. Vitrimers: Permanent organic networks with glass-like fluidity. Chem. Sci. 2016, 7, 30-38. [CrossRef] [PubMed]

3. Pritchard, R.H.; Redmann, A.L.; Pei, Z.; Ji, Y.; Terentjev, E.M. Vitrification and plastic flow in transient elastomer networks. Polymer 2016, 95, 45-51. [CrossRef]

4. Capelot, M.; Unterlass, M.M.; Tournilhac, F.; Leibler, L. Catalytic control of the vitrimer glass transition. ACS Macro Lett. 2012, 1, 789-792. [CrossRef]

5. Kloxin, C.J.; Bowman, C.N. Covalent adaptable networks: Smart, reconfigurable and responsive network systems. Chem. Soc. Rev. 2013, 42, 7161-7173. [CrossRef] [PubMed]

6. Winne, J.M.; Leibler, L.; Du Prez, F. Dynamic Covalent Chemistry in Polymer Networks: A Mechanistic Perspective. Polym. Chem. 2019, 10, 6091-6108. [CrossRef]

7. Lu, L.; Fan, J.; Li, G. Intrinsic healable and recyclable thermoset epoxy based on shape memory effect and transesterification reaction. Polymer 2016, 105, 10-18. [CrossRef]

8. Yu, K.; Taynton, P.; Zhang, W.; Dunn, M.L.; Qi, H.J. Reprocessing and recycling of thermosetting polymers based on bond exchange reactions. RSC Adv. 2014, 4, 10108-10117. [CrossRef]

9. Shi, Q.; Yu, K.; Dunn, M.L.; Wang, T.; Qi, H.J. Solvent Assisted Pressure-Free Surface Welding and Reprocessing of Malleable Epoxy Polymers. Macromolecules 2016, 49, 5527-5537. [CrossRef] 
10. Kaiser, S.; Wurzer, S.; Pilz, G.; Kern, W.; Schlögl, S. Stress relaxation and thermally adaptable properties in vitrimer-like elastomers from HXNBR rubber with covalent bonds. Soft Matter. 2019, 15. [CrossRef]

11. Tang, Z.; Liu, Y.; Guo, B.; Zhang, L. Malleable, Mechanically Strong, and Adaptive Elastomers Enabled by Interfacial Exchangeable Bonds. Macromolecules 2017, 50, 7584-7592. [CrossRef]

12. Cao, L.; Fan, J.; Huang, J.; Chen, Y. A robust and stretchable cross-linked rubber network with recyclable and self-healable capabilities based on dynamic covalent bonds. J. Mater. Chem. A 2019, 7, 4922-4933. [CrossRef]

13. Yang, Y.; Pei, Z.; Zhang, X.; Tao, L.; Wei, Y.; Ji, Y. Carbon nanotube-vitrimer composite for facile and efficient photo-welding of epoxy. Chem. Sci. 2014, 5, 3486-3492. [CrossRef]

14. Yang, Z.; Wang, Q.; Wang, T. Dual-Triggered and Thermally Reconfigurable Shape Memory Graphene-Vitrimer Composites. ACS Appl. Mater. Interfaces 2016, 8, 21691-21699. [CrossRef] [PubMed]

15. Hayashi, M.; Yano, R. Fair Investigation of Cross-Link Density Effects on the Bond-Exchange Properties for Trans-Esterification-Based Vitrimers with Identical Concentrations of Reactive Groups. Macromolecules 2020, 53, 182-189. [CrossRef]

16. Fortman, D.J.; Brutman, J.P.; Cramer, C.J.; Hillmyer, M.A.; Dichtel, W.R. Mechanically Activated, Catalyst-Free Polyhydroxyurethane Vitrimers. J. Am. Chem. Soc. 2015, 137, 14019-14022. [CrossRef]

17. Capelot, M.; Montarnal, D.; Tournilhac, F.; Leibler, L. Metal-catalyzed transesterification for healing and assembling of thermosets. J. Am. Chem. Soc. 2012, 134, 7664-7667. [CrossRef]

18. Brutman, J.P.; Delgado, P.A.; Hillmyer, M.A. Polylactide Vitrimers. ACS Macro Lett. 2014, 3, 607-610. [CrossRef]

19. Christophe, D.; Sebastien-jun, M.; Tournilhac Francois-genes; Ludwik, L. Titanium-Based Catalyst for Vitrimer Resins of Epoxy/Anhydride Type. U.S. Patent 20170044307, 16 February 2017.

20. Stukenbroeker, T.; Wang, W.; Winne, J.M.; Du Prez, F.E.; Nicolaÿ, R.; Leibler, L. Polydimethylsiloxane quenchable vitrimers. Polym. Chem. 2017, 8, 6590-6593. [CrossRef]

21. Liu, T.; Hao, C.; Wang, L.; Li, Y.; Liu, W.; Xin, J.; Zhang, J. Eugenol-Derived Biobased Epoxy: Shape Memory, Repairing, and Recyclability. Macromolecules 2017, 50, 8588-8597. [CrossRef]

22. Lewis, C.L.; Dell, E.M. A review of shape memory polymers bearing reversible binding groups. J. Polym. Sci. Part B Polym. Phys. 2016, 54, 1340-1364. [CrossRef]

23. Liu, T.; Hao, C.; Zhang, S.; Yang, X.; Wang, L.; Han, J.; Li, Y.; Xin, J.; Zhang, J. A Self-Healable High Glass Transition Temperature Bioepoxy Material Based on Vitrimer Chemistry. Macromolecules 2018, 51, 5577-5585. [CrossRef]

24. Wu, X.; Yang, X.; Yu, R.; Zhao, X.-J.; Zhang, Y.; Huang, W. A facile access to stiff epoxy vitrimers with excellent mechanical properties via siloxane equilibration. J. Mater. Chem. A 2018, 6, 10184-10188. [CrossRef]

25. Dizman, C.; Tasdelen, M.A.; Yagci, Y. Recent advances in the preparation of functionalized polysulfones. Polym. Int. 2013, 62, 991-1007. [CrossRef]

26. Rocks, J.; George, G.A.; Vohwinkel, F. Curing kinetics and thermomechanical behaviour of co-anhydride cured aminoglycidyl epoxy resins. Polym. Int. 2003, 52, 1758-1766. [CrossRef]

27. Mauri, A.N.; Riccardi, C.C. The effect of epoxy excess on the kinetics of an epoxy-anhydride system. J. Appl. Polym. Sci. 2002, 85, 2342-2349. [CrossRef]

28. Varma, I.K.; Gupta, V.B. Thermosetting Resin-Properties. In Comprehensive Composite Materials; Elsevier: Amsterdam, The Netherlands, 2000; pp. 1-56.

29. Paramarta, A.; Webster, D.C. Curing kinetics of bio-based epoxy-anhydride thermosets with zinc catalyst. J. Therm. Anal. Calorim. 2017, 130, 2133-2144. [CrossRef]

30. May, C. Epoxy Resins: Chemistry and Technology, 2nd ed.; CRC Press: Cleveland, OH, USA, 1987; ISBN 9780824776909.

31. Chen, J.; Soucek, M.D. Ultraviolet curing kinetics of cycloaliphatic epoxide with real-time fourier transform infrared spectroscopy. J. Appl. Polym. Sci. 2003, 90, 2485-2499. [CrossRef]

32. Trappe, V.; Burchard, W.; Steinmann, B. Anhydride-cured epoxies via chain reaction. 1. The phenyl glycidyl ether/phthalic acid anhydride system. Macromolecules 1991, 24, 4738-4744. [CrossRef]

33. Leukel, J.; Burchard, W.; Krüger, R.-P.; Much, H.; Schulz, G. Mechanism of the anionic copolymerization of anhydride-cured epoxies-Analyzed by matrix-assisted laser desorption ionization time-of-flight mass spectrometry (MALDI-TOF-MS). Macromol. Rapid Commun. 1996, 17, 359-366. [CrossRef] 
34. Barabanova, A.I.; Lokshin, B.V.; Kharitonova, E.P.; Afanasyev, E.S.; Askadskii, A.A.; Philippova, O.E. Curing cycloaliphatic epoxy resin with 4-methylhexahydrophthalic anhydride: Catalyzed vs. uncatalyzed reaction. Polymer 2019, 178, 121590. [CrossRef]

35. Corcuera, M.A.; Mondragon, I.; Riccardi, C.C.; Williams, R.J.J. Polymer networks derived from the anhydride curing of tetraepoxides. J. Appl. Polym. Sci. 1997, 64, 157-166. [CrossRef]

36. Couture, G.; Granado, L.; Fanget, F.; Boutevin, B.; Caillol, S. Limonene-based epoxy: Anhydride thermoset reaction study. Molecules 2018, 23, 2739. [CrossRef] [PubMed]

37. Musto, P.; Abbate, M.; Ragosta, G.; Scarinzi, G. A study by Raman, near-infrared and dynamic-mechanical spectroscopies on the curing behaviour, molecular structure and viscoelastic properties of epoxy/anhydride networks. Polymer 2007, 48, 3703-3716. [CrossRef]

38. Naar, N.; Lamouri, S.; Jeacomine, I.; Pron, A.; Rinaudo, M. A Comprehensive Study and Characterization of Colloidal Emeraldine-Base. J. Macromol. Sci. Part A 2012, 49, 897-905. [CrossRef]

(C) 2020 by the authors. Licensee MDPI, Basel, Switzerland. This article is an open access article distributed under the terms and conditions of the Creative Commons Attribution (CC BY) license (http://creativecommons.org/licenses/by/4.0/). 